\title{
Period Prevalence of Epilepsy in Children in BC: A Population-Based Study
}

\author{
Veronica Schiariti, Kevin Farrell, Jill S. Houbé, Sarka Lisonkova
}

\begin{abstract}
Background: Most estimates of the prevalence of seizure disorders in Canada derive from national surveys which differ in sampling and case-finding methods. This study used health care utilization data to make a population-based estimate of the prevalence of epileptic seizures and of epilepsy in children in British Columbia (BC). Methods: All BC residents between 0-19 years-of-age in 2002-3 enrolled in the Medical Services Plan were included. Epileptic seizures were defined using ICD-9 codes; health care utilization data was obtained from BC Linked Health Database. The period prevalence of epileptic seizures and of epilepsy was determined by age, urban/rural region and socioeconomic status. Results: 8,125 of 1,013,816 children were identified as having an epileptic seizure of which 5,621 were classified as epilepsy - 5.5 per 1,000 children (95\% CI: 5.4-5.7). The prevalence of epilepsy in infants and preschoolers was higher than that reported in the literature. A higher prevalence of epilepsy was observed also among those with low socioeconomic status. A higher prevalence of epilepsy was observed in those health regions with a higher proportion of First Nations and a lower prevalence was observed in health regions with a higher proportion of visible minorities. Conclusions: Age-specific prevalence rates in $\mathrm{BC}$ children for epilepsy, determined from population-based administrative records, were similar to published data except in children under five years. We found a gradient of increased prevalence with decreased level of income. Prevalence rates based on utilization data have the potential to guide program planning for children with epileptic seizures.
\end{abstract}

RÉSUMÉ: Étude de population sur la prévalence de l'épilepsie chez les enfants en Colombie-Britannique en 2002-2003. Contexte : La plupart des estimations de la prévalence de troubles convulsifs au Canada proviennent d'enquêtes nationales dont les méthodes d'échantillonnage et d'identification des cas sont différentes. Cette étude est basée sur les données d'utilisation des services de santé pour arriver à un estimé de la prévalence de crises épileptiques et d'épilepsie chez les enfants de la Colombie-Britannique (CB). Méthodes : Tous les résidents de la CB âgés de 0 à 19 ans en 2002-2003 et participant au Medical Services Plan ont été inclus dans l'étude. Les crises épileptiques ont été définies selon les codes ICD-9. Les données sur l'utilisation des services de santé ont été obtenues de la BC Linked Health Database. La prévalence des crises épileptiques et de l'épilepsie a été déterminée par âge, région urbaine ou rurale et statut socioéconomique. Résultats : 8125 enfants sur 1013816 ont été identifiés comme présentant des crises épileptiques dont 5621 étaient classifiées comme de l'épilepsie - 5,5 par 1000 enfants (IC à 95\% de 5,4 à 5,7). La prévalence de l'épilepsie chez les nourrissons et les enfants d'âge préscolaire était plus élevée que ce qui est rapporté dans la littérature. Une prévalence plus élevée d'épilepsie a été observée chez ceux dont le statut socioéconomique était faible. Une prévalence plus élevée a été observée dans les régions sanitaires possédant une plus forte proportion d'autochtones et une prévalence plus faible dans les régions sanitaires possédant une proportion plus élevée de minorités visibles. Conclusions : Les taux de prévalence par âge de l'épilepsie chez les enfants de la CB, selon les dossiers administratifs de population, étaient similaires aux données publiées sauf chez les enfants de moins de 5 ans. Nous avons constaté qu'il existe une augmentation graduelle de la prévalence en relation avec une diminution du niveau de revenu. Les taux de prévalence basés sur les données d'utilisation des soins de santé peuvent servir de guide à la planification de programmes destinés aux enfants présentant des crises épileptiques.

Can. J. Neurol. Sci. 2009; 36: 36-41

Most estimates of the prevalence of epilepsy in Canadian children derive from national surveys ${ }^{1,2}$. Limitations of these surveys include small sample sizes in the childhood age range that preclude analysis at the provincial level, and limited comparability between surveys due to different targeted age groups and sampling methodology. Epilepsy has a significant impact on children's health, quality of life academic progress and self-esteem. Cognitive, motor and/or psychiatric co-morbidity occur in $25-45 \%$ of children with epilepsy ${ }^{3-8}$. Similarly, Canadian survey data demonstrate that epilepsy carries a significant burden of illness, reflected in poorer health, psychosocial function and quality of life, and in higher use of health care resources ${ }^{9}$. Thus, prevalence studies of epilepsy are

From the Department of Pediatrics, British Columbia Children's Hospital (VS, KF, JSH), Centre for Community Child Health Research, Department of Pediatrics (VS, JSH), Centre for Health Innovation and Improvement, Department of Pediatrics (SL), University of British Columbia, Vancouver, British Columbia, Canada.

Received May 22, 2008. Final Revisions Submitted August 27, 2008.

Correspondence to: Veronica Schiariti, Centre for Community Child Health Research, University of British Columbia, Shaughnessy Bldg., L408-4480 Oak Street, Vancouver, British Columbia, V6H 3V4, Canada. 
useful in that they describe the burden of the disease in the population and help to determine the need for health care and to plan service delivery.

Few Canadian data exist on the prevalence of epilepsy in children $^{9,10}$. This study measured the period prevalence of epileptic seizures and of epilepsy in children living in British Columbia (BC) using health care utilization data and examined factors influencing the prevalence rates.

\section{METHODS}

This was a cross-sectional study of the period prevalence of epileptic seizures and of epilepsy in British Columbian children between January 1, 2002 and December 31, 2003 in which we examined the effect of residence in an urban or rural setting, neighbourhood income, and health regions.

\section{Study population}

Data were obtained on children aged 0 to 19 years between January 1, 2002 and December 31st, 2003 from the British Columbia Linked Health Database (BCLHD) at the University of $\mathrm{BC}$. The BCLHD ${ }^{11}$ is an administrative database comprised of core data on health services utilization and vital events for the residents of BC. Individual-level data on health care service use are collected by the BC Ministries of Health and other agencies for administrative purposes. The information in the BCLHD is linkable at the level of the individual. Because the health care system in BC is universal, these data represent a populationbased picture of utilization of these health care services. No identifiable data were utilized following data abstraction and linkage by the Centre for Health Services and Policy Research. Five databases were searched: 1) records of hospitalizations, 2) records of physician reimbursement, 3) birth registrations, 4) death records, and 5) the medical service plan (MSP) Registration and Premium Billing File.

Discharge abstracts for hospital services include information on up to 16 ICD-9-CM diagnostic codes, of which the first diagnosis is the primary diagnosis responsible for the hospital stay. Records of physician reimbursement for medical care provided are submitted under a fee-for-service arrangement, and contain information on patient diagnosis at the three-digit level of the ICD-9-CM classification system and physician specialty. The MSP registration file contains a record for every individual eligible to receive insured health services, and includes the individual's birth date, gender and geographic location.

\section{Case definitions and analyses}

Epileptic seizures were identified on the basis of the following ICD-9 CM codes: all ICD-9-CM codes for 345 for Epilepsy, 780 for Convulsions, 333 for Myoclonic seizures and V17.2 for Other/Epilepsy, documented in at least one physician claim or hospitalization record. Neonatal seizures were excluded (779.0 ICD-9 CM code). Cases of epilepsy included those in whom epilepsy was described as the primary diagnosis for that office visit or hospital admission. Thus, they would include active epilepsy and epilepsy in remission with treatment. Some children with epilepsy in remission without treatment would also be included when epilepsy was still considered to be the main diagnosis at that visit. The denominator was the population of children residing in BC as of January 1, 2002.
Children were localized to one of the five health regions in BC using the postal code of their place of residence. The geographic areas with $<10,000$ people were defined as rural and those with $>10,000$ people as urban. The neighbourhood income was used as a measure of the socioeconomic status (SES)) of the area and we stratified by lowest and highest income quintile according to Census data ${ }^{12}$. The prevalence of epilepsy and epileptic seizures was determined according to age. Prevalence rates were reported per 1000 children and compared across ages and regions at the $95 \%$ confidence level. Rural and urban neighbourhood income quintiles were created from Statistics Canada Census 2001 by aggregating household income data to the census enumeration area and ranking neighbourhood income quintiles from $20 \%$ of the population residing in the lowest income neighbourhoods to $20 \%$ of the population residing in the highest income neighbourhoods. The validity of using ecologic proxies for household income in the study of population health status has been demonstrated ${ }^{13}$. The proportion of visible minorities and of First Nations in each health region was obtained from Statistics Canada Census 2001. The Chi-square test was used to compare prevalence rates and neighbourhood income level as well as rates and urban and rural areas.

The study design followed the International League Against Epilepsy (ILAE) guidelines ${ }^{14}$. All aspects of the study design and data use were approved by the University of British Columbia's Research Ethics Board and the Children's and Women's Hospital Ethics Committee. A person-level analytic file was constructed to link all data relevant to the patient and patient identifiers were removed from the data file to maintain patient and provider anonymity.

In order to examine the face validity of the data in this study, we compared the prevalence of epilepsy with the rates described in the 2005 Canadian Community Health Survey (CCHS cycle $3.1)^{15}$ estimates. The CCHS BC sample included 1,817 epilepsy cases in children in BC. The CCHS is a cross sectional survey of the health determinants, health status and health system utilization of a representative sample of children (12-years-old and over) and adults in Canada.

\section{RESULTS}

Table 1 shows the age-specific prevalence rates for epileptic seizures and epilepsy in the $1,013,816$ children in BC. The overall prevalence of epileptic seizures was 8 per 1,000 children (95\% CI 7.8 - 8.2) and of epilepsy (all 345 ICD-9 CM codes) was 5.5 per 1,000 children (95\% CI 5.4-5.7). The seizures were classified as epilepsy (all 345 ICD-9 CM codes) in 69\%, convulsions (780 ICD-9 CM codes) in $17 \%$ and other/epilepsy and myoclonic seizures (V17.2 + 333 ICD-9 CM codes) in $0.5 \%$. The prevalence of epileptic seizures and of epilepsy in the youngest age group were higher than in children five years-ofage and older. No differences in prevalence were found by gender.

In the 2005 Canadian Community Health Survey (CCHS) ${ }^{15}$, the unweighted numbers of cases per age group were as follow; four reported cases among 683 children (12 to 14 years-of-age group), six reported cases among 704 children (15 to 17 yearsof-age), and six reported cases among 430 children (18 to 19 years-of-age). Overall, weighted prevalence rate based on CCHS showed a total epilepsy prevalence of 4.9 per 1,000 children 
Table 1: Prevalence of epileptic seizures and epilepsy per 1,000 children by age group

British Columbia Linked Health Database (Administrative data)

\begin{tabular}{|c|c|c|c|c|c|}
\hline Age group & $\begin{array}{l}\text { Number of } \\
\text { ES Cases }\end{array}$ & $\begin{array}{c}\text { Number of } \\
\text { Epilepsy Cases }\end{array}$ & Number of Children & $\begin{array}{l}\text { Rate of Epileptic Seizure } \\
\text { per } 1,000(95 \% \mathrm{Cl})^{*}\end{array}$ & $\begin{array}{c}\text { Rate of Epilepsy per } \\
1,000(95 \% \mathrm{Cl})^{*}\end{array}$ \\
\hline $0-4$ years & 2,912 & 1,464 & 209,993 & $13.9(13.3-14.4)$ & $7(6.6-7.3)$ \\
\hline $5-9$ years & 1,750 & 1,338 & 243,879 & 7.2( 6.9-7.5) & $5.5(5.2-5.8)$ \\
\hline $10-14$ years & 1,620 & 1,351 & 272,296 & $5.9(5.6-6.2)$ & $5.0(4.7-5.2)$ \\
\hline $15-19$ years & 1,843 & 1,468 & 287,648 & $6.4(6.1-6.7)$ & $5.1(4.8-5.4)$ \\
\hline Total & 8,125 & 5,621 & $1,013,816$ & $8.0(7.8-8.2)$ & $5.5(5.4-5.7)$ \\
\hline
\end{tabular}

$\mathrm{CI}=$ confident interval; $\mathrm{ES}=$ epileptic seizures; *p-value $<0.001$, total comparisons Chi-square test

(aged 12 to 19 years-of-age). The CCHS included only children 12 years-of-age and older and comparisons were only among the older groups. Confidence intervals could not be estimated due to small number of children in the survey.

The prevalence of epilepsy was higher among children living in the lowest-SES quintile compared to those living in the highest-SES quintile (Table 2). This was significant only in the youngest and oldest age groups but there was a trend for a higher prevalence in the lowest-SES quintile in the other age groups. No differences were observed between children living in urban and rural settings although there was a trend towards higher rates of epilepsy were observed among the youngest and oldest groups.

The prevalence of epilepsy was higher in the Interior, Northern and the Vancouver Island regions (Table 3). These areas of the Province had a higher proportion of people living in the lowest SES-quintile, a higher proportion of First Nations and a lower proportion of visible minorities (Table 3).

\section{Discussion}

Measurement of prevalence is influenced by the method and thoroughness of case ascertainment. Studies that use the medical records of hospitals or specialists are more likely to miss milder

Table 2: Prevalence of epilepsy per 1,000 (95\% CI) according to socioeconomic status

\begin{tabular}{lcc}
\hline Age group & Lowest quintile & Highest quintile \\
0-4 years & $8.1(7.3-8.9)$ & $5.8(5.6-6.6)$ \\
$5-9$ years & $5.3(4.7-5.9)$ & $5.0(4.4-5.7)$ \\
10-14 years & $4.9(4.3-5.5)$ & $4.2(3.7-4.8)$ \\
$15-19$ years & $5.7(5.1-6.4)$ & $4.5(3.9-5.0)$ \\
\hline
\end{tabular}

$\mathrm{CI}=$ confident interval cases. In one study in Poland, interview of a random sample of the population demonstrated that up to $27 \%$ of cases would have been missed if ascertainment over the previous five years had used medical records ${ }^{16}$. Surveys may also have weaknesses. In the 2005 Canadian Community Health Survey (CCHS cycle $3.1)^{15}$, a cross sectional survey of the health determinants, health status and health system utilization of a representative sample of children and adults in Canada, the presence of epilepsy was probed by an interviewer asking directly, "Do you have epilepsy diagnosed by a health professional?" Subjects responding "yes" were considered cases. In an Australian study ${ }^{17}$ that evaluated a questionnaire in a sample of people previously identified as having epilepsy, the survey data underestimated the reported

Table 3: Prevalence of epilepsy according to health region

\begin{tabular}{|c|c|c|c|c|c|}
\hline $\begin{array}{l}\text { Health } \\
\text { regions }\end{array}$ & $\begin{array}{l}\text { Number } \\
\text { of cases }\end{array}$ & $\begin{array}{l}\text { Number of } \\
\text { children }\end{array}$ & $\begin{array}{c}\text { Rate per } \\
1,000^{*}\end{array}$ & $\begin{array}{c}\text { Visible } \\
\text { minorities (\% } \\
\text { of population) }\end{array}$ & $\begin{array}{c}\text { First Nations } \\
\text { (\% of } \\
\text { population) }\end{array}$ \\
\hline Interior & 1,106 & 163,777 & 6.8 & 3.7 & 5.7 \\
\hline $\begin{array}{l}\text { Vancouver } \\
\text { Island }\end{array}$ & 933 & 157,582 & 5.9 & 6.3 & 5.1 \\
\hline Northern & 522 & 89,189 & 5.9 & 4.3 & 15.6 \\
\hline Fraser & 1,909 & 376,574 & 5.1 & 27.1 & 2.5 \\
\hline $\begin{array}{l}\text { Vancouver } \\
\text { Coastal }\end{array}$ & 1,151 & 226,269 & 5.1 & 41.8 & 2.4 \\
\hline
\end{tabular}

Visible minorities $=$ persons other than aboriginal people who are nonCaucasian in race or non-white in colour; *p value $<0.05$, Chi-square test 
prevalence by $23 \%$. Thus, the different methods have strengths and weaknesses and there is no recommended method of case ascertainment for epilepsy.

The prevalence of epilepsy in Canada has been estimated from national surveys ${ }^{1,2}$ and from administrative databases ${ }^{10}$. Variations in case definition, sampling methodology, as well as targeted age groups in national surveys limit comparability between surveys. In addition, small sample sizes in children have precluded analysis in that age group at the provincial level. This population-based study on the prevalence of epileptic seizures and epilepsy in children in BC, Canada, used ICD-9 CM grouped diagnoses from health care utilization data. The validity and reliability of grouped diagnosis using administrative databases have been found to be high for describing population health care utilization $^{10,18}$. Data analyzed using BCLHD has been shown to have higher validity when only the first three ICD-9 CM digits are used ${ }^{19}$. On the other hand, there are limitations of using the BCLHD. Misclassification bias may have resulted in the underor over-coding of epileptic seizures and co-morbidities by health professionals. As this was a cross-sectional study we were not able to review the ICD-9 diagnostic codes in a follow-up visit. In a prospective observational study ${ }^{20}$, diagnostic uncertainty between epileptic seizures and non-epileptic events was considered to be a factor in high rates of misdiagnosis. The authors found that non-epileptic events were twice as common as the epilepsies and epilepsy diagnosis was uncertain in $20 \%$ of cases of presentation. Physician fee-for-service reimbursement claims in some regions of $\mathrm{BC}$ are not consistently captured in the health care database which might result in underestimation. In addition, due to the presence of only one diagnosis per physician claim (MSP billing), our data have the potential to underestimate the prevalence of epilepsy. In a population based study in Manitoba, the criteria for diagnosis of epilepsy included at least one physician claim or hospital record or the receipt of at least one prescription for an antiepileptic drug ${ }^{10}$ whereas we did not access records of prescriptions of antiepileptic drugs. Other potential limitation of the use of administrative health care data is that they reflect how people use health care services, which may result in an underestimation of the disease prevalence.

Sixty-nine percent of cases of epileptic seizures were classified as epilepsy. The age-specific prevalence rates for epilepsy were similar to published data ${ }^{3,9,10}$ except in children under five years-of-age. It is possible that the higher prevalence of epilepsy among infants and preschoolers may reflect a misclassification bias. Thus, febrile seizures may have been misclassified as epilepsy in this age group. However, the prevalence of all epileptic seizures in this age group (13.9 per $1,000)$ was lower than the prevalence of febrile seizures in other studies $^{21}$. The inclusion of First Nations children may also have contributed to the higher prevalence in this age group. Thus, the SES of the First Nations population is much lower than that of the general population ${ }^{22}$. In addition, children under the age of five years represent $9 \%$ of the First Nations population but only $5 \%$ of the non-First Nations population according to 2001 Census data. Prevalence estimates may also vary among studies because of the lack of a uniform method for defining epilepsy and ascertaining cases for study. Given the similarities in case definition, data source, and study methodology we compared our estimates to Manitoba estimates ${ }^{10}$. The prevalence of epilepsy in
$\mathrm{BC}$ infants and preschoolers was two times higher than that in Manitoba. Variations in socio-demographic factors and exposure to risk factors may contribute to the difference between these provinces but this finding deserves further study.

The overall prevalence of epilepsy in this study was higher than that in the provincial survey data (Cycle 3.1, 2005) ${ }^{15}$. However, that survey data included only children older than 11 years and we were not able to validate our data against the CCHS survey estimates for the younger age groups. Although the CCHS sampled from approximately $98 \%$ of the Canadian population, it excluded particular populations, including those living in First Nation Reserves. The exclusion of populations that may be more predisposed to develop epilepsy because of socioeconomic or genetic factors might result in an underestimate of the prevalence. Indeed, the prevalence of epilepsy in this study was higher in those regions. In contrast to our findings, Kozyrskyj et $\mathrm{al}^{10}$ reported that the prevalence of epilepsy in a pediatric population estimated from Manitoba (Canada) administrative health care data was similar to the National Population Health Survey data, except in adolescents where the prevalence was higher than that reported in the National Population Health Survey. In spite of using differing methods of case ascertainment, most estimates of the prevalence of epilepsy in children are in the order of 4 to 5 per $1,000 .^{3,23-29}$ In contrast to our findings, these studies demonstrated that the prevalence of epilepsy increased with age, with rates ranging from approximately two to three per 1,000 children through age seven years ${ }^{23,27,29}$ to four to six per 1,000 children in 11 to 15 year olds ${ }^{26-29}$. Misclassification of febrile seizures as epilepsy in the younger age group in our study may have contributed to the difference that we observed.

Our study showed a higher prevalence of epilepsy in children living in low SES, particularly in the youngest and oldest groups. These findings are in keeping with studies from developing and developed countries which suggest higher prevalence rates among low income strata ${ }^{30,31}$. In a population-based study of Manitoba children that used administrative health care data, Kozyrskyj et $\mathrm{al}^{10}$ also observed a higher prevalence of epilepsy among children living in lower socioeconomic neighbourhoods in urban areas, which presented as a gradient of increased prevalence with decreased level of income. Moreover, the authors described that preschool children in the lowest income quintile were twice as likely as their counterparts in the highest income quintile to have seizure disorder. Different explanations have been proposed to explain these higher rates of seizure disorders among low income populations. Children living in low SES may have higher exposure rates to risk factors associated with epilepsy such as congenital anomalies of the central nervous system (CNS), birth asphyxia, CNS infections, and moderate to severe head trauma. , $8,32^{2}$

We observed that the prevalence of epilepsy in children varied significantly between the five Health Regions in BC (Table 3). Thus, the prevalence of epilepsy was higher in the Interior, Northern and Vancouver Island health regions than in the Vancouver Coastal or Fraser Valley regions. This difference may relate to several factors. The proportion of visible minorities (persons other than aboriginal people who are non-Caucasian in race or non-white in colour) was much higher in those two health regions that had the lowest prevalence of epilepsy. A higher 
prevalence of epilepsy in non-immigrants than in immigrants in Canada has been described previously in a report that analyzed two national health surveys ${ }^{2}$. This difference may be a manifestation of the "healthy immigrant effect". The incidence of many other chronic conditions in Canada has been demonstrated in adults to be lower in recent immigrants than in native-born people ${ }^{33}$. It is possible that healthier individuals are more likely to emigrate resulting in lower rates of chronic conditions such as epilepsy. The differences in proportion of First Nations children in each Health Region may also have played a role. Thus, the Northern, Interior and Vancouver Island health regions, which had a higher prevalence of epilepsy, have the highest percentage of First Nations $(15.6 \%, 5.7 \%$ and $5.1 \%$ respectively $)^{34}$. Furthermore, the percentage of First Nations children in these regions is even higher in that one fifth of the First Nations population is under 20 years-of-age, which is twice that of young people in the Canadian population ${ }^{35}$. We are not aware of any published studies on the prevalence of epilepsy studies in the First Nations population in Canada. However, a lower SES has been shown in this and other studies to increase the prevalence of epilepsy and over one half of First Nations adults are not working for pay ${ }^{35}$. There may also be genetic factors that predispose First Nations children to develop epilepsy. We are currently studying several First Nations families from British Columbia in which there are multiple members presenting during infancy with epilepsy ${ }^{36}$.

We observed no urban-rural differences in the prevalence of epilepsy in children in BC. This is similar to previous studies using both administrative databases and survey data. Kozyrskyj et $\mathrm{al}^{10}$ showed no urban-rural differences in prevalence of epileptic seizures in their population-based study in Manitoba. Similarly, in a comparison of two Canadian surveys, the National Population Health Survey (Cycle 3) and the Canadian Community Health Survey (Cycle 1.1), Tellez-Zenteno et $\mathrm{al}^{2}$ found a similar prevalence of epilepsy in populations living in urban and rural areas.

A benefit of this study is the comprehensiveness of the available data. In a region with universal medical coverage, it is very likely that the vast majority of the population living in the region are included in the study. The comprehensive data gives weight to the generalizability and applicability of our research findings. Our findings have the potential to guide program planning and service delivery in BC. In addition, we are planning to examine patterns of health service utilization of children with epilepsy by age groups in $\mathrm{BC}$.

\section{ACKNOWLEDGEMENTS}

This study was supported by the Michael Smith Foundation for Health Research and the British Columbia Epilepsy Society.

\section{REFERENCES}

1. McDougall J, Miller LT. Measuring chronic health condition and disability as distinct concepts in national surveys of school-aged children in Canada: a comprehensive review with recommendations based on the ICD-10 and ICF. Disabil Rehabil. 2003 Aug 19;25(16):922-39.

2. Tellez-Zenteno JF, Pondal-Sordo M, Matijevic S, Wiebe S. National and regional prevalence of self-reported epilepsy in Canada. Epilepsia. 2004 Dec;45(12):1623-9.
3. Cowan LD, Bodensteiner JB, Leviton A, Doherty L. Prevalence of the epilepsies in children and adolescents. Epilepsia. 1989 JanFeb;30(1):94-106.

4. Caplan R, Siddarth P, Stahl L, Lanphier E, Vona P, Gurbani S, et al. Childhood absence epilepsy: behavioral, cognitive, and linguistic comorbidities. Epilepsia. 2008 Jun 13. [Epub ahead of print].

5. Caplan R, Siddarth P, Gurbani S, Ott D, Sankar R, Shields WD. Psychopathology and pediatric complex partial seizures: seizurerelated, cognitive, and linguistic variables. Epilepsia. 2004 Oct; $45(10): 1273-81$.

6. Kavros PM, Clarke T, Strug LJ, Halperin JM, Dorta NJ, Pal DK. Attention impairment in Rolandic epilepsy: systematic review. Epilepsia. 2008 Apr 11. [Epub ahead of print].

7. Nelson KB, Ellenberg JH. Antecedents of seizure disorders in early childhood. Am J Dis Child. 1986;140(10):1053-61.

8. Cowan LD. The epidemiology of the epilepsies in children. Ment Retard Dev Disabil Res Rev. 2002;8(3):171-81.

9. Wiebe S, Bellhouse DR, Fallahay C, Eliasziw M. Burden of epilepsy: The Ontario health survey. Can J Neurol Sci. 1999 Nov;26(4): 263-70.

10. Kozyrskyj AL, Prasad AN. The burden of seizures in Manitoba children: a population-based study. Can J Neurol Sci. 2004 Feb;31(1):48-52.

11. Chamberlayne R, Green B, Barer ML, Hertzman C, Lawrence WJ, Sheps SB. Creating a population-based linked health database: a new resource for health services research. Can J Public Health. 1998 Jul-Aug;89(4):270-3.

12. Households and housing file, 2001 Census [homepage on the Internet]. Canada: Statistics Canada. [updated 2006 Jun 30; cited 2007 May 30]. Available from: http://www.statcan.ca/bsolc/ english $/$ bsolc? catno $=95 \mathrm{M} 0020 \mathrm{X}$.

13. Mustard CA, Derksen S, Berthelot JM, Wolfson M. Assessing ecologic proxies for household income: a comparison of household and neighbourhood level income measures in the study of population health status. Health Place. 1999 Jun;5(2): 157-71.

14. Guidelines for epidemiologic studies on epilepsy. Commission on epidemiology and prognosis, International League Against Epilepsy. Epilepsia. 1993 Jul-Aug;34(4):592-6.

15. Canadian Community Health Survey cycle 3 [homepage on the Internet]. Canada: Statistics Canada. [updated 2007 Jul 27; cited 2007 Dec 20]. Available from: http://www.chass.utoronto.ca/ datalib/codebooks/cstdli/cchs.htm\#cycle3_1.

16. Hauser WA, Hesdorffer DC. In epilepsy: frequency, causes and consequences. New York: Demos; 1990. p. 5-7.

17. Beran RG, Hall L, Michelazzi J. An accurate assessment of the prevalence ratio of epilepsy adequately adjusted by influencing factors. Neuroepidemiology. 1985;4(2):71-81.

18. Roos LL, Walld R, Uhanova J, Bond R. Physician visits, hospitalizations, and socioeconomic status: ambulatory care sensitive conditions in a Canadian setting. Health Serv Res. 2005;40(4):1167-85

19. Grunau GL, Sheps S, Goldner EM, Ratner PA. Specific comorbidity risk adjustment was a better predictor of 5-year acute myocardial infarction mortality than general methods. J Clin Epidemiol. 2006 Mar;59(3):274-80.

20. Beach R, Reading R. The importance of acknowledging clinical uncertainty in the diagnosis of epilepsy and non-epileptic events. Arch Dis Child. 2005 Dec;90(12):1219-22.

21. Sadleir LG, Scheffer IE. Febrile seizures. BMJ. 2007 Feb 10;334(7588):307-11.

22. 2001 Census Fast Facts: BC aboriginal identity population-income and low income [homepage on the Internet]. BC Stats. [updated 2004 Aug 30; cited 2007 Dec 21]. Available from: http://www.bcstats.gov.bc.ca/data/cen01/facts/cff0113.PDF.

23. Hauser WA, Annegers JF, Kurland LT. Prevalence of epilepsy in Rochester, Minnesota: 1940-1980. Epilepsia. 1991 Jul-Aug; 32(4):429-45.

24. Hauser WA. The prevalence and incidence of convulsive disorders in children. Epilepsia. 1994;35 Suppl 2:S1-6. 
25. Cockerell OC, Eckle I, Goodridge DM, Sander JW, Shorvon SD. Epilepsy in a population of 6000 re-examined: secular trends in first attendance rates, prevalence, and prognosis. J Neurol Neurosurg Psychiatry. 1995 May;58(5):570-6.

26. Sidenvall R, Forsgren L, Heijbel J. Prevalence and characteristics of epilepsy in children in northern Sweden. Seizure. 1996 Jun;5(2): 139-46.

27. Eriksson KJ, Koivikko MJ. Status epilepticus in children: aetiology, treatment, and outcome. Dev Med Child Neurol. 1997 Oct; 39(10):652-8.

28. Wallace H, Shorvon S, Tallis R. Age-specific incidence and prevalence rates of treated epilepsy in an unselected population of 2,052,922 and age-specific fertility rates of women with epilepsy. Lancet. 1998 Dec 19-26;352(9145):1970-3.

29. Kurtz Z, Tookey P, Ross E. Epilepsy in young people: 23 year follow up of the British national child development study. BMJ. 1998 Jan 31;316(7128):339-42.

30. Gomez JG, Arciniegas E, Torres J. Prevalence of epilepsy in Bogota, Colombia. Neurology. 1978 Jan;28(1):90-4.

31. Scott G. Prevalence of chronic conditions of the genitourinary, nervous, endocrine, metabolic, and blood and blood-forming systems and of other selected chronic conditions United States1973. Vital Health Stat 10. 1977 Mar;Series 10(109):1-72.
32. Nelson KB, Ellenberg JH. Predisposing and causative factors in childhood epilepsy. Epilepsia. 1987;28 Suppl 1:S16-24.

33. McDonald JT, Kennedy S. Insights into the 'healthy immigrant effect': Health status and health service use of immigrants to Canada. Soc Sci Med. 2004 Oct;59(8):1613-27.

34. Statistical profiles by health authorities [homepage on the Internet].BC Stats. [updated 2004 Nov 30; cited 2007 Dec 01]. Available from: http://www.bcstats.gov.bc.ca/data/cen01/abor/ haprof.asp.

35. First Nations Regional Longitudinal Health (RHS) survey 2002/03 national report [homepage on the Internet]. [updated 20062006 Mar 30; cited 2008 Apr 9]. Available from: http://rhs-ers.ca/ english/pdf/rhs2002-03reports/rhs_at_a_glance.pdf.

36. Demos M, Connolly M, Arbour L, Farrell K. In: Electro-clinical study of four First Nations families with benign familial infantile seizures. 10th International Child Neurology Congress; Montreal, Canada. Jun 2000. 